БОГУШЕВСКАЯ Ю. В., БАКИНА Ю. А.

ОСОБЕННОСТИ ТИПОВ ОТНОШЕНИЯ К БОЛЕЗНИ У ЖЕНЩИН...

Российский психологический жУРнАл, 2019, Т. 16, № 4, 22-33. doi: 10.21702/rpj.2019.4.2

МЕДИЦИНСКАЯ ПСИХОЛОГИЯ

УДК 159.9.072:616.89 doi: 10.21702/rpj.2019.4.2

Оригинальная научная статья

\title{
Особенности типов отношения к болезни у женщин с разной продолжительностью течения соматизированных расстройств
}

\author{
Юлия В. Богушевская, Юлия А. Бакина* \\ Федеральное государственное бюджетное образовательное учреждение высшего образования \\ «Курский государственный медицинский университет» Министерства здравоохранения Российской \\ Федерации, г. Курск, Российская Федерация \\ *E-mail: yuna.bulgakova@mail.ru
}

\section{ORCID ID: https://orcid.org/0000-0002-8340-0370}

\begin{abstract}
Аннотация
Введение. В статье рассматриваются особенности типов отношения к болезни у женщин с разной проАОлжительностью течения соматизированных расстройств. Полученные результаты могут быть полезны А^я Аостижения успешного ^ечебного взаимолействия межАу специалистами вторичной медицинской сети и пациентами с Аанным Аиагнозом. Изменение Аисгармоничного отношения к болезни является оАним из фракторов, способствующих вызАОровлению больного.

Метолы. Исследование проведено на женщинах, страдающих соматизированными рас-

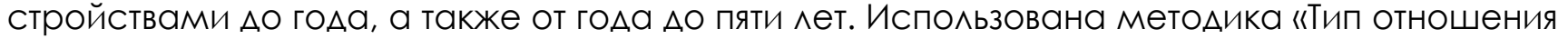
к болезни» ^. И. Вассермана с соавт. Аля определения типов отношения к болезни у женщин с разной проАолжительностью течения заболевания.

Результаты. Описаны статистически значимые различия в типах отношения к заболеванию у пациенток, стралающих соматизированными расстройствами более гола, и женщин с Алительностью болезни Ао гоАа. Установлено, что у женщин с Алительностью соматизированных расстройств более гола преоблаАает сенситивный тип отношения к болезни, характеризующийся повышенным беспокойством по отношению к своему заболеванию, что свидетельствует о нарушении социальной алаптации. У женщин с Алительностью заболевания АО гоАа преоблаАают типы отношения к болезни с интрапсихической направленностью, сопровожАающиеся ухо АОм в болезнь.

ОбсужАение результатов. Аанные провеАенного исслеАования свиАетельствуют о наличии Аисгармоничного отношения к болезни у женщин при разной Алительности соматизированных расстройств. Выявленные особенности отношения к болезни позволяют обосновать проведение психокоррекционных мероприятий.
\end{abstract}

\section{КАючевые слова}

соматизированное расстройство, отношение к болезни, внутренняя картина болезни, Алительность заболевания, сенситивность, расстройство телесного Аистресса, социальная Аезалаптация, интерпсихическая направленность, интрапсихическая направленность, психологическая коррекция 
БОГУШЕВСКАЯ Ю. В., БАКИНА Ю. А.

ОСОБЕННОСТИ ТИПОВ ОТНОШЕНИЯ К БОЛЕЗНИ У ЖЕНЩИН...

РосСиЙский псИХологИЧЕСКИй ЖУРнАл, 2019, Т. 16, № 4, 22-33. doi: 10.21702/rpj.2019.4.2

МЕДИЦИНСКАЯ ПСИХОЛОГИЯ

\section{Основные положения}

$\triangleright$ отношение к болезни у женщин с разными сроками заболевания при соматизированном расстройстве является Аисгармоничным;

ру женщин при соматизированном расстройстве Алительностью более гола в отличие от пациенток, болеющих менее года, преобладает сенситивный тип отношения к болезни с интерпсихической направленностью, характеризующейся социальной Аезалаптацией; $\triangleright$ у женщин при соматизированном расстройстве Алительностью $А$ гоАа преоблаАают типы отношения к болезни с интрапсихической направленностью, что сопровожАается «уходом в болезны, в отличие от пациенток, страдающих соматизированным расстройством более го $\Delta \mathrm{a}$.

\section{Для цитирования}

Богушевская, Ю. В. и Бакина, Ю. А. (2019). Особенности типов отношения к болезни у женщин с разной продолжительностью течения соматизированных расстройств. Российский психологический журнал, 16(4), 22-33. doi: 10.21702/rpj.2019.4.2

Дата получения рукописи: 09.10.2019

Дата окончания рецензирования: 22.12.2019 Дата принятия к публикации: 25.12.2019

\section{Введение}

Соматизированные расстройства (CР) относятся к числу соматоформных (F45) в МКБ-10 и проявляются множественными соматическими функциональными симптомами, сопровождающими больных в течение 2-х лет и более. У лиц, страдающих СР, присутствуют постоянные требования медицинских обследований, которые не верифицируют какое-либо заболевание. Такие пациенты продолжают оставаться проблемой для специалистов первичной медицинской сети, т. к. зачастую отказываются следовать их рекомендациям обратиться за специализированной психиатрической помощью (Погосов и Богушевская, 2019; Боброва, 2012; Чижова, 2012; Собенников, 2014; Наумова, Куприянова и Белобородова, 2014).

В МКБ-11 соматоформные расстройства переименованы в расстройство телесного дистресса (РТД) по причине признания специалистами стигматизирующего влияния на пациентов термина «соматоформный». Немаловажно отметить, что в данной классификации предлагается решение проблемы диагностики РТД не на основе отсутствия физических или медицинских причин (как при соматоформных расстройствах в МКБ-10), а посредством выделения компонентов, которые присутствуют - обеспокоенность, чрезмерные мысли и поведение, направленное на поиск соматического заболевания (Gureje \& Reed, 2016; First \& Fisher, 2012; Reed et al., 2019; Pohontsch et al., 2018). В связи с этим выявление особенностей реагирования на заболевание будет являться ценным диагностическим материалом в работе клинических психологов и психиатров.

Преувеличение негативного значения субъективных симптомов при СР формирует у больных искаженное представление о причинно-следственных связях в развитии недуга, что также является одним из факторов «избегающего врача-психиатра поведения». Поэтому осознание роли психологических механизмов в развитии заболевания лицами, страдающими СР, увеличивает шансы обращения к специалистам нужного профиля. 
БОГУШЕВСКАЯ Ю. В., БАКИНА Ю. А.

ОСОБЕННОСТИ ТИПОВ ОТНОШЕНИЯ К БОЛЕЗНИ У ЖЕНЩИН...

Российский психологический жУРнАл, 2019, Т. 16, № 4, 22-33. doi: 10.21702/rpj.2019.4.2

МЕДИЦИНСКАЯ ПСИХОЛОГИЯ

Совокупность телесных ощущений, эмоциональные переживания, оценка своего состояния и информация о нем формируют отношение к болезни. При СР оно часто бывает дисгармоничным, что может способствовать хронизации заболевания, привести к психической и социальной дезадаптации больного (Погосов и Богушевская, 2017).

Диагноз «соматизированное расстройство», несмотря на весомый прогресс психофармакологии, на сегодняшний день имеет плохой терапевтический прогноз (Погосов, Ласков и Богушевская, 2018; Рупчев, 2001). В связи с этим, эмпирический поиск должен быть направлен на выявление дополнительных коррекционных мишеней, одну из которых представляет тип отношения к болезни. Для того чтобы понимать, каким образом формируется дисгармоничное отношение к болезни у лиц, страдающих СР, важно учитывать не только клинические проявления данного заболевания, но и патологические особенности личности, такие как демонстративность, склонность к формированию рентных установок по отношению к физическому состоянию, что отражается на социальном функционировании таких пациентов (Карвасарский, 1990; Квасенко, 1980).

Формирование соматизированных симптомов происходит не только за счет конверсионных процессов (предполагающих символический смысл болезненных физических ощущений), но и в результате механизма соматизации (выражения эмоционального дискомфорта и психологического стресса языком физических симптомов) (Александер, 2006; Barsky, Orav, \& Bates, 2005).

Следует отметить, что существующие теоретические представления о соматизации часто не относятся к описанию сферы внутреннего телесного опыта, в которой переживается ощущение боли. Данное обстоятельство послужило возрастанию исследований телесности и ее участия в механизме соматизации. Например, в работе Рупчева (2001) у пациентов, страдающих соматоформными расстройствами, отмечаются ограниченность возможности определения интрацептивных ощущений, отсутствие развитой системы взаимодействия с внутренним телесным опытом, а также семантическая «метафоричность» внутренней телесности. По мнению автора, соматизация создает условия для возникновения патологических физических ощущений и направленного на них «чрезмерного» внимания. Также для данной категории больных свойственна отчужденность душевных и телесных феноменов.

Постановка диагноза «соматизированное расстройство» сказывается на социальном функционировании пациента и сопровождается выраженным беспокойством, немотивированной тревогой и нарушениями эмоционального реагирования. Так, Урванцев (2000) утверждает, что лица с высоким уровнем алекситимии часто высказывают соматические жалобы, что можно рассматривать как проявление соматизации аффекта. Наличие алекситимных черт при СР приводит к специфическим особенностям выстраивания межличностных взаимоотношений у данной категории пациентов.

По мнению Филимонова (2011), повышенная тревога у пациентов, госпитализированных в психиатрическое учреждение с диагнозом «соматоформное расстройство», в отличие от лиц, не имеющих опыта обращения к психиатру, обусловлена стигматизацией. Автор установил, что для данных пациентов характерно преобладание тревожного, обессивно-фобического и неврастенического типов отношения к болезни. У лиц, страдающих соматоформными расстройствами и наблюдающихся в первичной медицинской сети, преобладает анозогнозический вариант реагирования на болезнь, что связано с отсутствием понимания истинных причин функциональных симптомов и нежеланием признавать наличие психического расстройства. 
БОГУШЕВСКАЯ Ю. В., БАКИНА Ю. А.

ОСОБЕННОСТИ ТИПОВ ОТНОШЕНИЯ К БОЛЕЗНИ У ЖЕНЩИН...

РосСИйский псИХологИЧЕСКИй ЖУРнАл, 2019, Т. 16, № 4, 22-33. doi: 10.21702/rpj.2019.4.2

МЕДИЦИНСКАЯ ПСИХОЛОГИЯ

На формирование дисгармоничного типа отношения к болезни при СР оказывают влияние и типологические особенности личности, которые отмечаются во многих исследованиях (Прибытков и Еричев, 2017; Tomenson et al., 2012). Ранее большое значение в развитии СР придавалось наличию истерических черт. В настоящее время получены результаты о роли преморбидного склада личности других типов (с преобладанием тревожных, сенситивных, шизоидных, пограничных и других черт), что не позволяет рассматривать истерические черты личности как единственные, характерные для больных СР (Чижова, 2012; Собенников, 2014; Прибытков, Юркова и Баженова, 2016; Tomenson et al., 2012; Lenze, Miller, \& Munir, et al., 1999).

Помимо этого, существуют исследования, в которых указывается, что с усугублением течения данного расстройства формируется соматизированное развитие личности, при котором происходит уменьшение соматических симптомов, и в клинической картине начинают превалировать патохарактерологические расстройства (Александровский, 2006; Ушаков, 1978).

При анализе рациональной составляющей отношения к болезни у лиц, страдающих СР, согласно A. Martin, W. Rief, был выявлен когнитивный стиль с катастрофизацией телесных ощущений, что выступает феноменом, способствующим развитию и поддержанию функциональных симптомов при СР. Данным пациентам свойственны высказывания анозогнозического типа. Отрицание своего болезненного состояния может быть связано с ситуацией неопределенности, характером заболевания, типом течения, возрастом (Martin \& Rief, 2011; Salkovskis, Warwick, Deale, et al., 2003; Брябрина, 2009).

Salkovskis et al. (2003) также выделяют особый когнитивный стиль пациентов с диагнозом «соматоформное расстройство», который характеризуется наличием дезадаптивных установок по отношению к здоровью и медицине, например, таких как: «здоровье есть тогда, когда нет никаких нарушений», «боль в эпигастральной области - язва желудка». При этом знания о связи между соматическими и психическими процессами могут быть неглубокими или же вообще отсутствовать. Такая когнитивная оценка больными СР своего состояния определяет настороженность и тревогу относительно телесной перцепции и способствует развитию ипохондрического фабулирования.

Излишнее беспокойство по поводу имеющихся нарушений тесно взаимосвязано не только с недостатком когнитивных представлений пациентов о болезни, но и со специфическими особенностями телесного опыта личности, что также является существенным фактором для формирования дисгармоничного отношения к болезни (Глазырина, Солодков, Кулыгин, Юсупов и Ятманов, 2016; White, McDonnell, \& Gervino, 2011; Рассказова, 2013). Так, согласно данным Т. Д. Василенко, в структуре переживания телесного опыта при соматоформных расстройствах преобладает негативный аффект при трудности в выражении эмоций, а также склонность к интерпретации такими больными физиологических ощущений не как нормальных, а как патологических (Василенко и Мангушев, 2018; Юндалова и Николаевская, 2017).

Изучая особенности отношения к болезни при соматоформных расстройствах, Чижова (2012) выявила в своих исследованиях наличие тревожно-депрессивного настроения у данных пациентов. Преобладающими типами отношения к болезни были ипохондрический и неврастенический.

Своеобразный феномен «бегства в болезнь», по мнению Менделевича и Соловьевой (2002), характерный для СР и других невротических расстройств, является уклонением от трезвой оценки реальности и неспособностью разрешить внутренний конфликт.

Таким образом, исходя из теоретико-методологического анализа литературных источников по данной проблеме, можно заключить, что основу дезадаптивного варианта отношения 
БОГУШЕВСКАЯ Ю. В., БАКИНА Ю. А.

ОСОБЕННОСТИ ТИПОВ ОТНОШЕНИЯ К БОЛЕЗНИ У ЖЕНЩИН...

Российский психологический жУРнАл, 2019, Т. 16, № 4, 22-33. doi: 10.21702/rpj.2019.4.2

МЕДИЦИНСКАЯ ПСИХОЛОГИЯ

к болезни при СР составляют различные компоненты. Так, существенное влияние оказывают клинические особенности самого заболевания, осознание их фрустрирующего характера и угрозы для личности, связанные с этим когнитивные искажения, эмоциональные нарушения, специфические характеристики внутреннего телесного опыта, дисгармоничные типы отношения к болезни.

В настоящем исследовании осуществлена диагностика типов отношения к болезни на индивидуальном уровне, а также дан ответ на вопрос о том, каким образом отличаются типы отношения к болезни у женщин с продолжительностью течения СР до года и от года до 5 лет.

Целью исследования явилось изучение типа отношения к болезни при разной продолжительности течения соматизированных расстройств.

\section{Методы}

В выборке 1-ую группу составили женщины, страдающие СР до года ( $\mathrm{n}=28)$, с первичным обращением в психиатрическое учреждение; 2-ую группу - женщины, страдающие СР более года $(\mathrm{n}=28)$, госпитализированные повторно. Средний возраст в обеих группах приблизительно равен 44,5 годам. Работающих пациенток больше в 1-ой группе (88,8 \% и 55,5\% соответственно). В этой же группе количество незамужних женщин, и имеющих высшее образование также оказалось выше (77,7\% и 33,3\%, 44,4\% и 11,1\%, соответственно). В обеих выборках большинство женщин имеют детей (88,8\% и 77,7\%). Длительность заболевания в 1-ой группе составила до года (дата первого обращения 2018-2019), а во 2-ой группе - от 1 года до 5 лет (дата первого обращения 2012-2017).

Для диагностики типов отношения к болезни при СР была использована методика «Тип отношения к болезни» (ТОБОЛ) Л. И. Вассермана с соавт. При создании ТОБОЛ была использована клинико-психологическая типология отношения к болезни, предложенная А. Е. Личко и Н. Я. Ивановым в 1980 г. Выделяются 12 типов отношения к болезни, которые были включены авторами в условно-адаптивный блок (гармоничный, эргопатический, анозогнозический типы), блоки с интрапсихической направленностью (тревожный, ипохондрический, неврастенический, апатический, меланхолический типы) и интерпсихической направленностью (эгоцентрический, сенситивный, дисфорический, паранойяльный типы). Последние два блока характеризуются нарушением психической и социальной адаптации. Также диагностируются три возможных типа отношения к болезни: «чистый»-доминирует один тип, «смешанный»до 3-х типов, «диффузный»- от 3-х и выше (Вассерман, Иовлев, Карпова и Вукс, 2005).

\section{Результаты}

В ходе экспериментального исследования нами были рассмотрены различия в типах отношения к болезни у женщин при СР с разной длительностью заболевания. При подсчете результатов был использован непараметрический критерий U Манна - Уитни, т. к. распределение признаков отличается от нормального.

Из 12-ти возможных типов отношения к болезни нами были обнаружены статистически значимые различия при высоком уровне статистической достоверности лишь по сенситивному типу отношения к болезни. Данные сравнительного анализа типов отношения к болезни в группе женщин с разной длительностью СР представлены в таблице 1. 
БОГУШЕВСКАЯ Ю. В., БАКИНА Ю. А.

ОСОБЕННОСТИ ТИПОВ ОТНОШЕНИЯ К БОЛЕЗНИ У ЖЕНЩИН...

РосСиЙский псИХологИЧЕСКИй ЖУРнАл, 2019, Т. 16, № 4, 22-33. doi: 10.21702/rpj.2019.4.2

МЕДИЦИНСКАЯ ПСИХОЛОГИЯ

\begin{tabular}{|c|c|c|c|}
\hline \multicolumn{4}{|c|}{$\begin{array}{l}\text { Таблица } 1 \\
\text { Сравнительный анализ типов отношения к болезни при СР с разной Алительностью } \\
\text { заболевания }\end{array}$} \\
\hline Переменные & p-level & $\frac{\text { Cредние значения }}{(\Delta о \text { го } \Delta \mathrm{a})}$ & $\frac{\text { Cредние значения }}{\text { (более года) }}$ \\
\hline Гармоничный & $p=0,451285$ & 8,22222 & 13,55556 \\
\hline Эргопатический & $p=0,754690$ & 17,33333 & 16,11111 \\
\hline Анозогнозический & $p=0,203006$ & 9,88889 & 0,44444 \\
\hline Тревожный & $p=0,214710$ & 14,33333 & 19,22222 \\
\hline ИпохонАрический & $p=1,000000$ & 16,00000 & 15,00000 \\
\hline Неврастенический & $p=0,506923$ & 16,33333 & 12,55556 \\
\hline Меланхолический & $p=0,787628$ & 10,00000 & 8,77778 \\
\hline Апатический & $p=0,893584$ & 7,66667 & 6,22222 \\
\hline Сенситивный & $p=0,028503^{* *}$ & 18,55556 & 33,55556 \\
\hline Эгоцентрический & $p=0,626136$ & 13,00000 & 12,44444 \\
\hline Паранойяльный & $p=0,329132$ & 6,22222 & 8,77778 \\
\hline Аисорорический & $p=0,690496$ & 8,55556 & 10,00000 \\
\hline
\end{tabular}

Условные обозначения:

* - различия обнаружены на уровне статистической тенленции $(0,05<p \leq 0,1)$;

** - различия обнаружены на Аостоверном уровне статистической значимости $(0,01<p \leq 0,05)$;

*** - различия обнаружены на высоком уровне статистической значимости $(p \leq 0,01)$.

Для сенситивного типа отношения к болезни с интерпсихической направленностью характерны трудности социальной адаптации, связанные с нарушениями межличностного взаимодействия и обусловленные преморбидными особенностями личности.

Пациентки с длительностью СР более года склонны испытывать беспокойство и озабоченность возможным неблагоприятным впечатлением, которое может произвести на окружающих информация об их болезни, в отличие от пациенток, страдающих СР до года. Женщины с выраженным сенситивным типом отношения к болезни не хотят, чтобы посторонние и близкие люди проявляли к ним жалость или считали их обузой. Для них характерны ранимость и колебания настроения, связанные с межличностными контактами. Мы предполагаем, что сенситивный тип отношения к болезни, преобладающий у пациенток с длительностью СР более года, может быть связан как с феноменом стигматизации, так и с желанием выглядеть в глазах окружающих здоровым человеком. Результаты представлены на рисунке 1. 
БОГУШЕВСКАЯ Ю. В., БАКИНА Ю. А.

ОСОБЕННОСТИ ТИПОВ ОТНОШЕНИЯ К БОЛЕЗНИ У ЖЕНЩИН...

Российский психологИческий ЖХУРнАл, 2019, Т. 16, № 4, 22-33. doi: 10.21702/rpj.2019.4.2

МЕДИЦИНСКАЯ ПСИХОЛОГИЯ

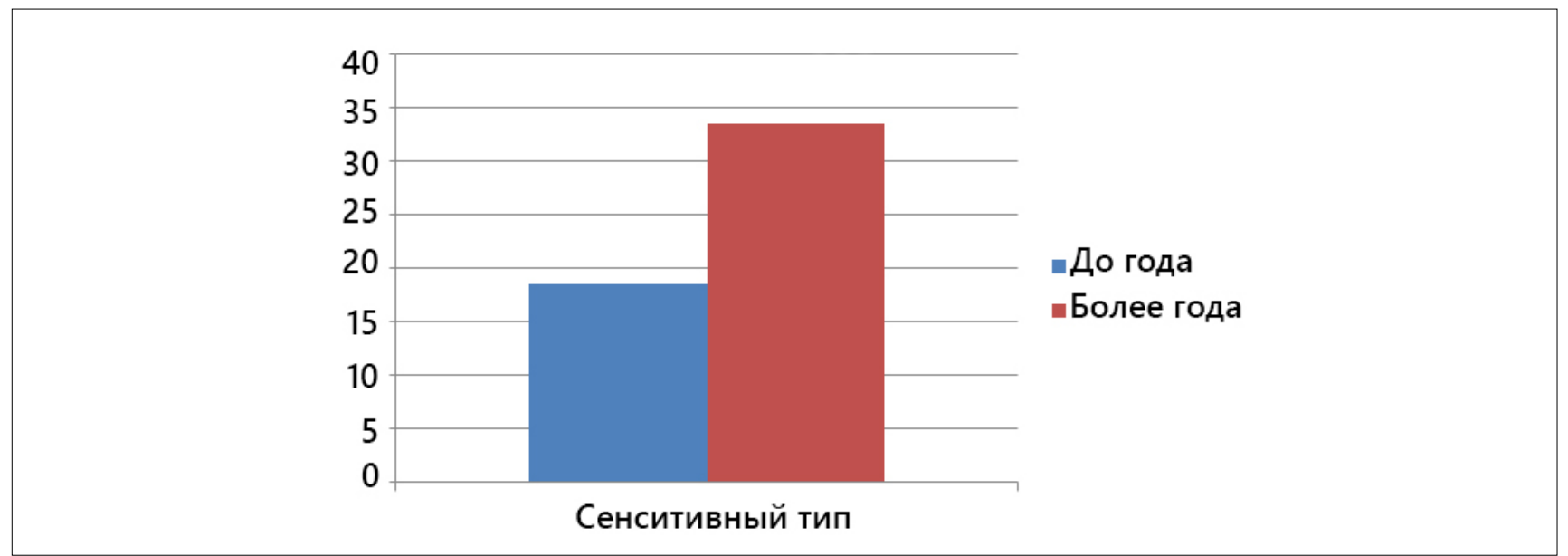

Рисунок 1. Гистограмма различий в среАних значениях по сенситивному типу отношения к болезни у женщин при СР с разной Алительностью заболевания

Далее нами был осуществлен сравнительный анализ частоты встречаемости типов отношения к болезни по показателю «сохранение/нарушение психической и социальной адаптации» у женщин, страдающих СР, с разной продолжительностью течения заболевания, с помощью использования критерия $\chi^{2}$ Пирсона. Результаты исследования представлены в таблице 2.

\begin{tabular}{|lcc|}
\hline \multicolumn{1}{|l|}{ Таблица 2} & \\
Значимость различий по частоте проявлений разных вилов направленности личностного \\
реагирования на болезнь при СР с различной прололжительностью заболевания
\end{tabular}


БОГУШЕВСКАЯ Ю. В., БАКИНА Ю. А.

ОСОБЕННОСТИ ТИПОВ ОТНОШЕНИЯ К БОЛЕЗНИ У ЖЕНЩИН...

РосСиЙский псИХологИЧЕСКИй ЖУРнАл, 2019, Т. 16, № 4, 22-33. doi: 10.21702/rpj.2019.4.2

МЕДИЦИНСКАЯ ПСИХОЛОГИЯ

Нами были обнаружены статистически значимые различия по частоте проявлений типов отношения к болезни с интерпсихической и интрапсихической личностными направленностями реагирования на болезнь.

Таким образом, у женщин с длительностью СР более года частота встречаемости интерпсихической направленности личностного реагирования на болезнь выше по сравнению с пациентками, страдающими СР менее года.

Для женщин с продолжительностью течения СР до года характерна высокая частота встречаемости интрапсихической направленности личностного реагирования на СР, что может быть связано с «уходом в болезнь», негативно отражающимся на эмоциональной сфере больных (преобладание тревожности, подавленности, реакций по типу раздражительной слабости). Полученные результаты представлены на рисунках 2 и 3.

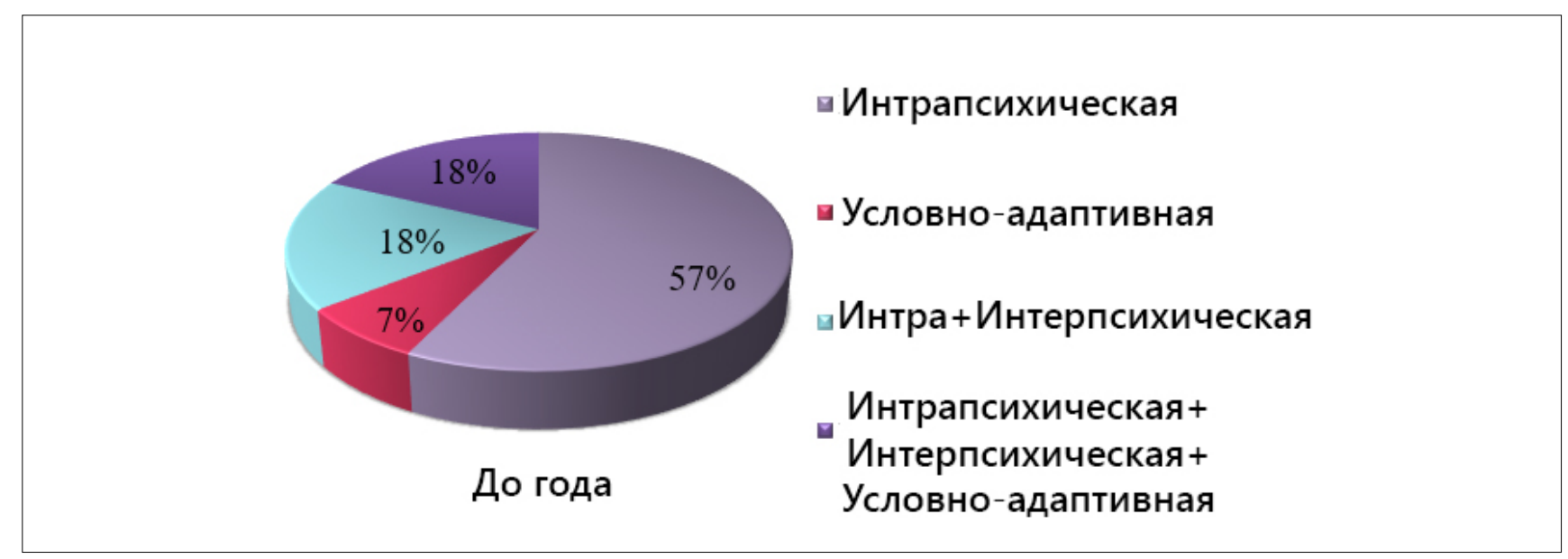

Рисунок 2. Аиаграмма распределения частоты встречаемости разных виАов направленности Аичностного реагирования на болезнь при Алительности СР АО ГоАа

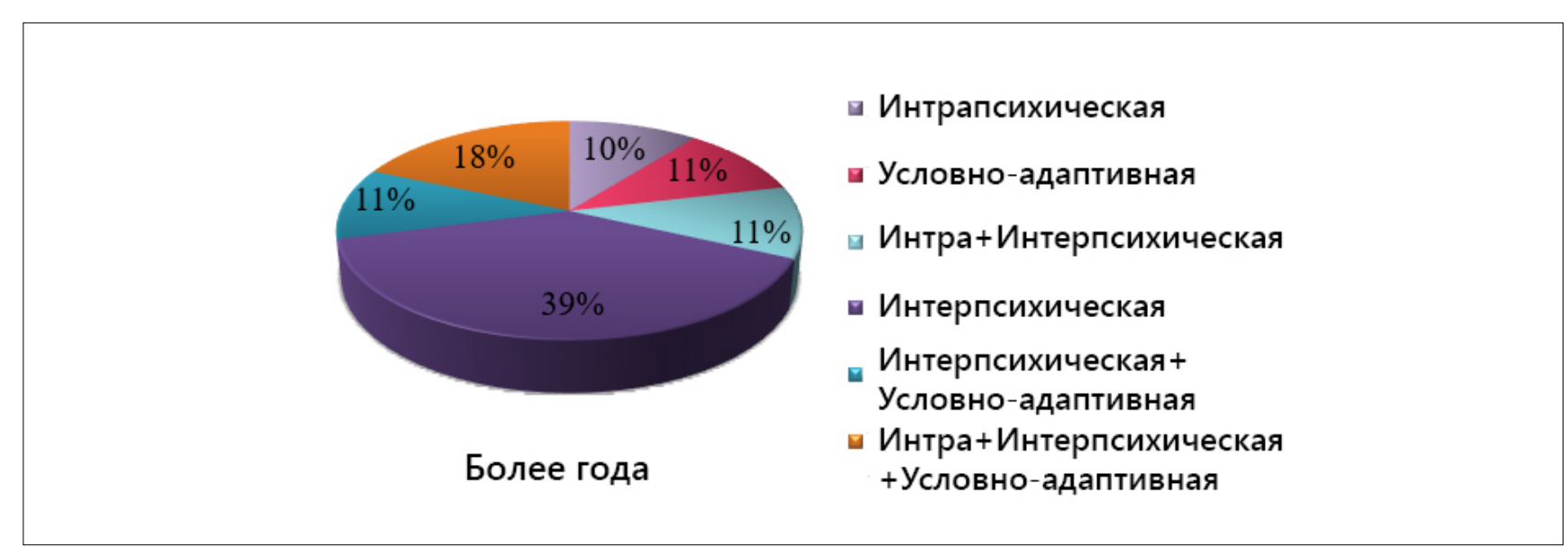

Рисунок 3. Аиаграмма распределения частоты встречаемости разных виАов направленности мичностного реагирования на болезнь при Алительности СР более гола 
БОГУШЕВСКАЯ Ю. В., БАКИНА Ю. А.

ОСОБЕННОСТИ ТИПОВ ОТНОШЕНИЯ К БОЛЕЗНИ У ЖЕНЩИН...

Российский психологический жУРнАл, 2019, Т. 16, № 4, 22-33. doi: 10.21702/rpj.2019.4.2

МЕДИЦИНСКАЯ ПСИХОЛОГИЯ

Таким образом, полученные результаты свидетельствуют о том, что в обеих группах испытуемых наблюдается нарушение психической и социальной адаптации.

\section{Обсуждение результатов}

В целом, полученные данные свидетельствуют о наличии дисгармоничного отношения к болезни у женщин при разной длительности СР.

Нами были получены статистически значимые различия между двумя группами больных по сенситивному типу отношения к болезни, что свидетельствует о нарушении социальной адаптации у женщин, страдающих СР более года. При исследовании частоты встречаемости возможных направленностей личностного реагирования на болезнь также были обнаружены статистически значимые различия. У пациенток при СР длительностью более года выражены типы отношения к болезни, характеризующиеся интерпсихической направленностью, в отличие от пациенток, страдающих СР до года, у которых преобладает интрапсихическая направленность. Такое отношение к болезни у женщин при СР с продолжительностью течения более года может быть обусловлено преморбидными особенностями личности, феноменами «стигматизации» и «самостигматизации», что нуждается в дальнейшем рассмотрении вопроса (Елфимова и Елфимов, 2009).

«Уход в болезнь», наблюдающийся у пациенток с длительностью заболевания до года, на наш взгляд, возможен из-за их сосредоточенности на болезненных ощущениях, развития «ипохондризации» личности, приобретения «вторичной выгоды» от заболевания.

Полученные нами результаты не противоречат данным многочисленных исследований, направленных, в частности, на изучение внутренней картины болезни при невротических расстройствах, где для пациентов характерны такие типы отношения к болезни, как неврастенический, ипохондрический и тревожный, соответствующие интрапсихической направленности личностного реагирования на болезнь (Брябрина, 2009; Глазырина и др., 2016; Михайлова, Ястребов и Ениколопов, 2002).

Женщины, страдающие СР, при продолжительности течения до года, характеризуются «внутренним переживанием» болезни, эмоциональной погруженностью в себя и симптоматику. В этом периоде происходит, как правило, процесс адаптации к болезни, который может привести при хронизации СР к смещению фокуса внимания с себя на окружающих и «использованию» симптомов «в своих целях», для коммуникации с другими людьми, что характерно для пациенток, страдающих СР на протяжении длительного времени (Merskey, 2004).

Практическая ценность настоящего исследования состоит в том, что выявленные нами особенности отношения к болезни позволили обосновать направление психологической коррекционной работы, целью которой является формирование гармоничного отношения к болезни и лечению при СР. Ее задачами являются:

- сформировать представления о влиянии психологических факторов на развитие соматизированных расстройств;

- повысить способность распознавания, дифференциации и понимания эмоций и сопровождающих их когнитивных процессов;

- сформировать адаптивное поведение в условиях заболевания;

- развить социальные навыки и межличностного взаимодействия.

Также, исходя из полученных результатов, можно выделить мишени для психотерапевтической коррекции: 
БОГУШЕВСКАЯ Ю. В., БАКИНА Ю. А.

ОСОБЕННОСТИ ТИПОВ ОТНОШЕНИЯ К БОЛЕЗНИ У ЖЕНЩИН...

РосСиЙский псИХологИЧЕСКИй ЖУРнАл, 2019, Т. 16, № 4, 22-33. doi: 10.21702/rpj.2019.4.2

МЕДИЦИНСКАЯ ПСИХОЛОГИЯ

1) коррекция индивидуального уровня реагирования на болезнь у женщин, страдающих СР до года, должна быть направлена на смещение фокуса с процесса «ипохондрического» развития личности в сторону проработки внутренних психологических проблем;

2) коррекция индивидуального уровня реагирования на болезнь у женщин, страдающих СР более года, должна быть направлена на снижение высокого уровня сенситивности в межличностных контактах.

Таким образом, на фоне постоянных и длительных контактов с медицинскими службами у лиц, страдающих СР, происходят значительные нарушения в социальной сфере функционирования личности, что подтверждается наличием индивидуальных дисгармоничных типов отношения к болезни, препятствующих физическому и психологическому благополучию. Для осуществления профессиональной психологической помощи данной категории больных необходимо дальнейшее изучение структуры отношения к болезни для целостного понимания того, каким образом при СР формируется дисгармоничное отношение к болезни, как оно изменяется в процессе течения заболевания и какие «мишени воздействия» будут нуждаться в коррекции.

\section{Литература}

Александер, Ф. (2006). Психосоматическая медицина. Принципы и применения (А. М. Боковикова, В. В. Старовойтова, пер. с англ.). М.: Ин-т общегуманитарных исследований.

Александровский, Ю. А. (2006). Некоторые узловые вопросы современной пограничной психиатрии. Психиатрия и психофармакотерапия, 8(2), 4-13.

Боброва, М. А. (2012). Эмоциональные, когнитивные и личностные нарушения при соматоформных расстройствах (типология, терапия и прогноз) (кандидатская диссертация). Москва.

Брябрина, Т. В. (2009). Особенности отношения к здоровью и болезни при соматоформной вегетативной дисфункции у лиц молодого возраста. Вестник Южно-Уральского государственного университета. Серия: Психология, 18(151), 80-85.

Василенко, Т. Д. и Мангушев, Ф. Ю. (2018). Телесный опыт и его роль в структуре социальной фрустрированности у больных соматоформными расстройствами. Психология. Историкокритические обзоры и современные исследования, 7(2А), 38-45.

Вассерман, Л. И., Иовлев, Б. В., Карпова, Э. Б. и Вукс, А. Я. (2005). Психологическая диагностика отношения к болезни: Пособие для врачей. Санкт-Петербург: Санкт-Петербургский научно-исследовательский психоневрологический институт им. В. М. Бехтерева.

Глазырина, Т. М., Солодков, А. С., Кулыгин, С. В., Юсупов, В. В. и Ятманов, А. Н. (2016). Особенности вклада внутренней картины болезни и класса заболевания на уровень нервно-психической адаптации пациентов. Ученые записки университета имени П. Ф. Лесгафта, 6(136), 218-221.

Елфимова, Е. В. и Елфимов, М. А. (2009). Личность и болезнь: «внутренняя картина болезни», качество жизни и приверженность лечению. Заместитель главного врача, 11, 18-25.

Карвасарский, Б. Д. (1990). Неврозы: Руководство для врачей (2-е изд., перераб. и доп.). М.: Медицина.

Квасенко, А. В. (1980). Психология больного. Л.: Медицина.

Менделевич, В. Д. и Соловьева, С. Л. (2002). Неврозология и психосоматическая медицина. Москва: МЕДпресс-информ. 
БОГУШЕВСКАЯ Ю. В., БАКИНА Ю. А.

ОСОБЕННОСТИ ТИПОВ ОТНОШЕНИЯ К БОЛЕЗНИ У ЖЕНЩИН...

Российский психологический жУРнАл, 2019, Т. 16, № 4, 22-33. doi: 10.21702/rpj.2019.4.2

МЕДИЦИНСКАЯ ПСИХОЛОГИЯ

Михайлова, И. И., Ястребов, В. С. и Ениколопов, С. Н. (2002). Клинико-психологические и социальные факторы, влияющие на стигматизацию психически больных разных нозологических групп. Журнал неврологии и психиатрии им. С. С. Корсакова, 7, 58-65.

Наумова, Е. Л., Куприянова, Е. И. и Белобородова, Э. И. (2014). Адаптивные копинг-стратегии у пациентов с синдромом раздраженного кишечника. Сибирский вестник психиатрии и наркологии, 2(83), 62-64.

Погосов, А. В. и Богушевская, Ю. В. (2017). Клинические, личностно-психологические и социально-демографические факторы, препятствующие обращению больных соматизированными расстройствами за специализированной помощью. Сибирский вестник психиатрии и наркологии, 4(97), 22-30. doi: 10.26617/1810-3111-2017-4(97)-22-30

Погосов, А. В. и Богушевская, Ю. В. (2019). Проблема соматизированных расстройств: клиника, непрофильное обращение за медицинской помощью, психообразование. Обозрение психиатрии и медицинской психологии имени В. М. Бехтерева, 3, 64-72. doi: 10.31363/2313-7053-2019-3-64-72

Погосов, А. В., Ласков, В. Б. и Богушевская, Ю. В. (2018). Причины необоснованного обращения больных соматизированными расстройствами к врачам общемедицинской практики. Неврология, нейропсихиатрия, психосоматика, 10, 40-45. doi: 10.14412/2074-2711-2018-4-40-45

Прибытков, А. А. и Еричев, А. Н. (2017). Соматоформные расстройства. Часть вторая: методика когнитивно-поведенческой психотерапии. Обозрение психиатрии и медицинской психологии, 2, С. 10-16.

Прибытков, А. А., Юркова, И. О. и Баженова, Ю. Б. (2016). Структура личности и механизмы психологической защиты при соматоформных расстройствах. Социальная и клиническая психиатрия, 26(2), 31-35.

Рассказова, Е. И. (2013). Роль нарушений когнитивной и эмоциональной регуляции в возникновении соматических симптомов. Вопросы психологии, 6, 87a-97.

Рупчев, Г. Е. (2001). Психологическая структура внутреннего телесного опыта при соматизации: На модели соматоформных расстройств (кандидатская диссертация). Москва.

Собенников, В. С. (2014). Соматизация и соматоформные расстройства. Доступ 27 июня 2019, источник https://psychiatr.ru/news/344?pag e=117

Урванцев, Л. П. (2000). Алекситимия как фактор психосоматических заболеваний. В Л. П. Урванцев Психология соматического больного. Ярославль: Ярослав. гос. ун-т.

Ушаков, Г. К. (1978). Пограничные нервно-психические расстройства. Москва.

Филимонов, А. П. (2011). Отношение к болезни пациентов с соматоформными расстройствами, наблюдающихся в психиатрических и общесоматических медицинских учреждениях. Сибирский вестник психиатрии и наркологии, 5(68), 28-30.

Чижова, А. И. (2012). Клинико-психологические аспекты патогенеза соматоформных невротических расстройств. Вестник Южно-Уральского государственного университета, 6, 138-144.

Юндалова, Т. А. и Николаевская, А. О. (2017). Особенности телесности пациентов с расстройствами невротического спектра (на примере соматоформных расстройств). В И. Э. Есауленко (ред.), Организация амбулаторно-поликлинической помощи в России: проблемы и перспективы их решения: Материалы межвузовской студенческой научно-практической конференции по результатам научно-исследовательской работы (С. 380-382). Москва: Перо. 
Barsky, A. J., Orav, E. J., \& Bates, D. W. (2005). Somatization increases medical utilization and costs independent of psychiatric and medical comorbidity. Arch. Gen. Psychiatry, 62(8), 903-910. doi: 10.1001/archpsyc.62.8.903

First, M. B., \& Fisher, C. E. (2012). Body-integrity identity disorder: The persistent desire to acquire a physical disability. Psychopathology, 45(1), 3-14. doi: 10.1159/000330503

Gureje, O., \& Reed, G. M. (2016). Bodily distress disorder in ICD-11: Problems and prospects. World Psychiatry, 15(3), 291-292. doi: 10.1002/wps.20353

Lenze, E. J., Miller, A. R., \& Munir, Z. B. et al. (1999). Psychiatric symptoms endorsed by somatization disorder patients in a psychiatric clinic. Annals of Clinical Psychiatry, 11(2), 73-79. doi: 10.1023/A:1022342431514

Martin, A., \& Rief, W. (2011). Relevance of cognitive and behavioral factors in medically unexplained syndromes and somatoform disorders. Psychiatric Clinics of North America, 34(3), 565-578. doi: 10.1016/j.psc.2011.05.007

Merskey, H. (2004). Somatization, hysteria, or incompletely explained symptoms? The Canadian Journal of Psychiatry, 49(10), 649-651. doi: 10.1177/070674370404901001

Pohontsch, N. J., Zimmermann, T., Jonas, C., Lehmann, M., Löwe, B., \& Scherer, M. (2018). Coding of medically unexplained symptoms and somatoform disorders by general practitioners - an exploratory focus group study. BMS Family Practice, 19, 129. doi: 10.1186/s12875-018-0812-8

Reed, G. M., First, M. B., Kogan, C. S., Hyman, S. E., Gureje, O., Gaebel, W., ... Saxena, S. (2019). Innovations and changes in the ICD-11 classification of mental, behavioural and neurodevelopmental disorders. World Psychiatry, 18(1), 3-19. doi: 10.1002/wps.20611

Salkovskis, P. M., Warwick, H. M., Deale, A. C., et al. (2003). Cognitive-behavioral treatment for severe and persistent health anxiety (hypochondriasis). Brief Treatment and Crisis Intervention, 3(3), 353. doi: 10.1093/brief-treatment/mhg026

Tomenson, B., McBeth, J., Chew-Graham, C., MacFarlane, G., Davies, I., Jackson, J. ... Creed, F. (2012). Somatization and health anxiety as predictors of health care use. Psychosomatic Medicine, 74(6), 656-664. doi: 10.1097/PSY.0b013e31825cb140

White, K. S., McDonnell, C. J., \& Gervino, E. V. (2011). Alexithymia and anxiety sensitivity in patients with non-cardiac chest pain. Journal of Behavior Therapy and Experimental Psychiatry, 42(4), 432-439. doi: 10.1016/j.jbtep.2011.04.001

Конфликт интересов отсутствует 